\section{Inovação tecnológica e} desenvolvimento;

2. Tecnologia e acumulação de capital em escala internacional;

3. Progresso técnico e acumulação;

4. Inovação de processos e de produtos;

5. O sistema de produção capitalista e o mercado internacional

Henrique Rattner *

* Professor do Departamento de Fundamentos Sociais e Jurídicos da Administração da Escola de Administração de Empresas de São Paulo da Fundação Getulio Vargas.

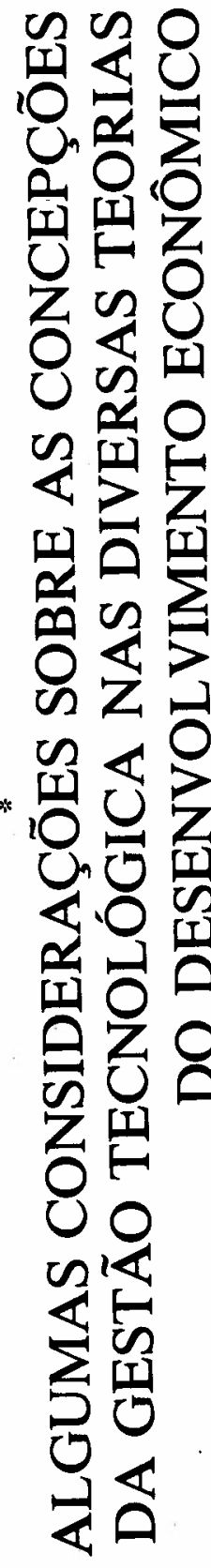

Desde o início do projeto as equipes de pesquisa enfrentaram o seguinte dilema:

Partir de um enfoque sistêmico funcionalista da administração tecnológica nas empresas, com objetivos pragmáticos de melhorar as técnicas de gestão e de aperfeiçoar os conhecimentos e práticas relacionados com a inovação, transferência e administração da tecnologia, ou insistir numa análise prévia das condições histórico-estruturais em que se realizam as operações tecnológicas em economias dependentes e de crescimento capitalista tardio.

No primeiro caso, a pesquisa limitar-se-ia a aspectos específicos da gestão tecnológica nas empresas, a um nivel empírico e com categorias e conceitos fixos, à imagem das outras áreas técnicas ensinadas nas escolas de administração. A tecnologia, neste caso, seria considerada como uma variável independente, cujo conhecimento e controle permitiriam elevar a performance das empresas e, por extensão, resolveriam os problemas do desenvolvimento nacional.

A segunda visão encara a tecnologia, ou melhor, as inovações técnicas como processos inerentes ao sistema capitalista e, como tal, resultado de determinadas relações sociais de produção, que se manifestam tanto ao nivel da empresa individual, quanto das economias nacional e internacional. Neste caso, a gestão tecnológica ao nível da empresa, por mais perfeita e amparada em conhecimentos teóricos e práticos da administração, não seria capaz de explicar toda a complexidade das determinações econômicas e políticas que cerceiam e limitam a atuação das empresas, em economias dependentes e tecnicamente atrasadas.

Desde os primeiros seminários de discussão e elaboração de documentos, manifestou-se certa polarização entre os pesquisadores em termos de uma postura teórica microeconômica e funciónalista, por um lado, e uma visão macroeconômica e histórica das relações de produção, como marco de referência, por outro. Os que adotaram a primeira posição, admitiam explicitamente, como premissas básicas da pesquisa, a possibilidade de "administrar" a inovação tecnológica na empresa, de acordo com um processo decisório visando à otimização da escolha diante de uma série de alternativas dadas. Neste contexto, foi introduzido o conceito de "tecnologia adequada", significando aquela que otimizasse certos parâmetros considerados representativos do sucesso da firma. Esta posição, contudo, se torna bastante vulnerável ao ampliar-se a discussão, incluindo nela e confrontando os conceitos de racionalidade da empresa e racionalidade social. ${ }^{1}$

O segundo grupo partiu do pressuposto da tecnologia como uma variável dependente, condicionada por e estreitamente relacionada com o nível das forças produtivas e as relações sociais de produção, as quais determinariam, nos mercados nacional e internacional, os níveis de demanda, de investimentos e, conseqüentemente, de emprego e de acumulação.

A essas divergências teóricas profundas correspondem também objetivos diferentes: à busca das falhas e escolhas "irracionais" dos empresários e suas eventuais causas, seguiriam prescrições minuciosas so- 
bre as técnicas mais eficientes de administrar tecnologias, levando, em última análise, a uma "racionalização" das empresas latino-americanas, sua maior capacidade de enfrentar a concorrência nos mercados externos e, assim, ao "desenvolvimento econômico". Do outro lado, aspirava-se, antes de mais nada, a obter uma explicação aceitável sobre o porquê de determinado comportamento tecnológico dos empresários e administradores latino-americanos, deduzido inicialmente mediante uma análise histórico-estruturalista do processo de acumulação e reprodução capitalista nesses países, cujas hipóteses seriam testadas na investigação empírica.

As notas que seguem procuram sintetizar as diferentes abordagens do progresso técnico e sua relação com o desenvolvimento.

\section{INOVAÇÃO TECNOLÓGICA E DESENVOLVIMENTO}

O objetivo destas notas introdutórias é de proporcionar alguns marcos de referência para a análise dos dados empíricos coletados durante a pesquisa, submetendo à apreciação e discussão as diversas abordagens encontradas na literatura econômica. Não se pretende com estas notas introdutórias esgotar o assunto, mas tão-somente apontar diferentes posiçð̌es teóricas que, necessariamente, levam a esquemas analiticos e explicativos diferentes.

Uma primeira indagação se levanta sobre a origem, natureza e função da tecnologia no processo produtivo. Sem negar o impacto exercido pelas inovaçðes técnicas sobre máquinas e equipamentos produtivos, a relação real procede em ordem inversa, ou seja, considerando a tecnologia como conhecimento humano aplicado à produçăo, o problema a investigar seriam as formas de determinação do desenvolvimento tecnológico pela dinâmica e racionalidade do processo de produção social. Dado o marco institucional capitalista em que se desenrola nossa análise, consideramos a tecnologia, sob todas as formas possíveis (máquina, equipamento, desenho, etc.), como uma mercadoria cuja produção e comercialização refletem os interesses daqueles que dominam e controlam a produção e os mercados - nacionais e internacionais - nos quais competem por posiçðes monopolisticas.

À medida que o sistema capitalista se expande e aprofunda através de movimentos cíclicos, são intensificados os processos de concentração e centralização do capital, o que afeta sensivelmente a produçăo, a comercialização e a transferência de tecnologia em mercados nacionais e internacionais. As notas seguidas procuram focalizar as abordagens das teorias nen. clássica, estruturalista, de dependência e de acumulação de capital, referentes à dinâmica da inovaçăo tecnológica no sistema capitalista.

\subsection{Visão neo-clássica}

As doutrinas elaboradas pelos adeptos desta escola partem da premissa básica do mercado de "concorrência perfeita", em que a tecnologia ou a forma de combinação dos fatores de produção seria determinada pe- lo custo dos fatores aplicados na produção de bens e serviços. O "progresso" técnico ou a inovação manifestar-se-á nos aumentos da produção obtidos pelo uso de certas máquinas ou de recursos humanos e sua funçăo precípua seria conseguir maior eficiência de uma determinada combinaçăo de fatores de produção. Essa função de produçăo (combinação de fatores) representa um quadro técnico estático, ao nível da firma individual, do qual é impossível passar ao nível agregado da economia. Outro ponto vulnerável encontramos na hipótese de substituibilidade dos fatores de produção entre si, a partir da qual se constroem outros, tais como a homogeneidade dos fatores e sua respectiva produtividade, que determinaria sua remuneração ou preços de equilíbrio. 2

Estudando o "progresso técnico", a teoria neoclássica o considera como um "resíduo" ou uma diferença no nível de produção além daquele atribuível ao capital e ao trabalho separadamente, mensurável mediante um coeficiente input-output, e transformado numa espécie de terceiro fator de produção, exógeno ao modelo econômico. Daí surgiram os modelos do progresso técnico "incorporado" no capital ou no trabalho, assumindo que melhorias técnicas podem ser fixadas em certas máquinas ou homens, diferentes qualitativamente dos anteriores, e que representariam uma função de produção específica, em que o progresso técnico assume a forma de uma tendência ao crescimento da produtividade física, determinada, em última análise, pelo investimento bruto. ${ }^{3}$ Essa colocação torna visível uma relação contraditória entre o progresso técnico e a taxa de obsolescência; na medida em que aumentasse a velocidade da introdução de novas máquinas, elevar-se-ia também o crescimento do produto. Por outro lado, a taxa de depreciação afeta positivamente a incorporação de novas máquinas, reduzindo os custos de produção e incrementando a produtividade média. Assim se explica a tendência à obsolescência precoce dos produtos e equipamentos e sua eventual transferência para as economias menos desenvolvidas.

As idéias-chave dessa teoria, com relação à inovação tecnológica, podem ser resumidas da seguinte forma. 4

a) toda tecnologia è "datada" e "localizada", seu grau de otimização depende do "meio-ambiente" específico, no qual está sendo utilizada;

b) o problema chave é a produção (geração) de técnicas, e não tanto seu uso (importação, transferência, assimilação e adaptação);

c) a produção de técnicas depende do nível e da estrutura de produção do sistema;

d) o crescimento do produto depende da velocidade da inovaçåo tecnológica, a qual, por sua vez, é alimentada por uma taxa mais elevada de depreciação das máquinas e equipamentos. 
Apesar de sua formulação e aparente rigor matemáticos, o poder explanatório dessa teoria, quanto à natureza e dinâmica do progresso técnico, é bastante reduzido porque fenômenos tais como a acumulação de capital, as taxas de lucro, a internacionalização da produção e a estrutura monopolística dos mercados, quando mencionadas, o são de forma marginal ao "progresso técnico".

\subsection{A teoria estruturalista da CEPAL}

Partindo da análise das características típicas da estrutura produtiva das economias latino-americanas, os membros mais proeminentes da CEPAL (Raul Prebisch, Celso Furtado, Anibal Pinto, etc.) delas derivam e explicam a evolução histórica, o subdesenvolvimento do subcontinente ${ }^{5} \mathrm{e}$ as diferentes fases e problemas da industrialização.

As mudanças na estrutura da produção interna são explicadas como respostas aos problemas criados pelo tipo de participação das economias latinoamericanas no comércio internacional. Sem questionar a irracionalidade do sistema econômico internacional, os economistas da CEPAL enfatizam a necessidade de transformar a estrutura de produção interna (geralmente caracterizada pela dicotomia dos setores "moderno" e "tradicional") a fim de conseguir uma participação mais equitativa (economicamente mais lucrativa) no comércio internacional. O modelo de crescimento advogado é orientado para o mercado interno, o que implica em desenvolvimento industrial. Essa visão puramente economicista dos problemas de desenvolvimento, abstrai dos seus aspectos sócio-políticos e, por isso, não parece apta para explicar a evolução histórica e, menos ainda, prognosticar saídas reais para o dilema.

Contudo, apesar das conotaçōes pró-capitalistas da ideologia desenvolvimentista cepaliana, é preciso fazer justiça e reconhecer aos seus autores os méritos da crítica ao pensamento neo-clássico, referente às vantagens comparativas, à suposta difusão dos frutos do progresso técnico e às teses de Rostow sobre as etapas do crescimento econômico. Por outro lado, apontaram também algumas das contradições do processo de substituição das importações - o crescimento do sub e desemprego, o processo inflacionário etc. - nos modelos de desenvolvimento adotado. Focalizaremos, resumidamente, o papel da tecnologia na análise cepaliana do subdesenvolvimento latino-americano.

No modelo de crescimento "para fora", sua dinâmica depende da demanda por produtos primários dos países industrializados ou, em outras palavras, $o$ crescimento da produção interna e do emprego depende do incremento das exportaçס̃es. $\mathrm{Na}$ medida em que estas encontram pontos de estrangulamento, devido ao esgotamento ou dificuldades de acesso a certos recursos naturais e produtivos, ocorrem importaçōes tecnológicas (máquinas, equipamentos, pessoal qualificado, etc.) bem como um certo grau de sua adaptação e assimilação. Contudo, como esses processos tecnológicos foram desenvolvidos para servir à racionalidade do Capital (reduzir custos e aumentar os lucros), eles tendem a ser capital intensivo, com toda uma sequiência de efeitos econômicos e sociais negativos, manifestos, sobretudo, na existência de um mercado interno, de bases extremamente restritas, formado e dominado pelos consumidores das classes média e alta, da população urbana. A estreiteza do "mercado doméstico" está assim perfeitamente relacionada com a "demanda externa", determinante da dinâmica desse modelo de acumulação baseado no setor de exportaçðes. Em consequêencia, a "política" tecnológica necessária ao funcionamento da economia envolve o emprego de máquinas e equipamentos relativamente sofisticados no setor de exportação, enquanto se importam, também, bens de consumo duráveis e de luxo, de tecnologia bastante avançada. Finalmente, surge uma incipiente produção doméstica de bens de consumo, a qual depende de insumos importados e de tecnologias incorporadas ou não-incorporadas.

Nessas condiçðes, o setor de exportação apresenta altos indices de produtividade e de lucratividade usufruindo de condiçð̃es operacionais muito favoráveis (livre câmbio, incentivos fiscais, baixos custos de produção, etc.), o que atrai mais investimentos para este setor, ou para atividades econômicas estreitamente relacionadas com ele. Por outro lado, o Estado proporciona os recursos necessários ao crescimento "para fora", financiando ou subsidiando a infra-estrutura $e$ serviços públicos (portos, transportes, comunicaçōes, habitaçðes, etc.).

Segundo a linha de análise dos representantes da CEPAL, qualquer esforço visando expandir e diversificar a estrutura produtiva interna, isto é, planos de industrialização, necessitaria de altos níveis de acumulação por depender da importação de tecnologias sofisticadas e caras, cuja aquisição só seria possivel com recursos originados das exportaçð̃es. Entretanto, o setor externo é extremamente vulnerável face a flutuaçðes de preços e de demanda externa e, por outro lado, durante a Segunda Guerra, as receitas de exportação aumentaram, enquanto as possibilidades de importação foram bastante diminuídas, tornando, assim, viável o desenvolvimento da produção doméstica para o mercado interno.

Atribuindo ao modelo de crescimento "para fora" a culpa pelos problemas e desequilíbrios estruturais que obstaculizam um desenvolvimento normal da "substituição das importaçōes", os teóricos da CEPAL condenam implicitamente as oligarquias agroexportadoras, enquanto manifestam sua aprovação e apoio à burguesia industrial e à tecnocracia estatal .

Com referência à tecnologia utilizada, a industrialização por substituição das importaçōes, concentrando seus esforços inicialmente em bens de consumo leve, recorre a soluções tecnológicas poupadoras de mão-de-obra, o que determina uma baixa capacidade de absorção da mão-de-obra, face a um crescimento populacional acelerado. Gerar empregos suficientes exigiria uma elevação substancial do investimento interno, prejudicada pelos baixos níveis de renda e de poupança. Por outro lado, a indivisibilidade de certos equipamentos e técnicas produtivas resulta em escalas de produção maiores do que as necessidades dos estreitos mercados locais ou regionais. Manifesta-se assim uma certa correlação entre niveis elevados de sub e de- 
semprego, devido à capitalização excessiva em alguns ramos da produção e à falta de recursos para investimentos em outros ramos de atividade. A escassez de recursos para impulsionar o processo de industrialização seria devido, em boa parte, à estrutura arcaica da propriedade fundiária, prevalecendo os lati e minifúndios, com baixa produtividade.

Como solução ao problema de poupança para o desenvolvimento, os economistas cepalianos propōem uma reforma agrária que transformaria a agricultura numa base efetiva da industrialização capitalista. Advogando amplas reformas sociais - redistribuição de renda, criação de empregos, descentralização e descentralização do sistema produtivo, etc. - a CEPAL postula um papel mais ativo para as classes média e alta (burguesia), no processo de acumulação interna, apoiadas por um aparato estatal capaz e desejoso de planejar e promover o desenvolvimento.

\subsection{A teoria da dependência e dependência tecnológica}

$\mathrm{Na}$ década dos anos 60 , com o estancamento do processo de substituição das importações, os problemas apontados pelos economistas da CEPAL tornaram-se mais graves, a ponto de se questionar radicalmente 0 modelo de desenvolvimento industrial adotado. Incapacidade de gerar empregos, dificuldades com o balanço de pagamentos, aumento da dívida externa, acompanhados por uma queda nas atividades extrativas e agrícolas, formaram o pano de fundo de uma situação em que proliferaram populações "marginalizadas" nos centros urbanos, enquanto a distribuição das rendas se tornava cada vez mais regressiva.

O enfoque analítico de economistas e sociólogos deslocou-se para os investimentos estrangeiros, como causa da evasão de divisas e, portanto, de recursos para investimentos, o que induziria a uma dependência crescente, haja vista a necessidade de aumentar as importações. Os investimentos estrangeiros passaram a ser considerados como vetores para a instalação de estruturas produtivas monopolisticas, nos países subdesenvolvidos, baseadas em tecnologias capital intensivas e subutilizando a capacidade instalada, porém operando com baixos custos de produção e preços administrados, que proporcionam altas taxas de retorno sobre o investimento. Desta situação surge também o controle monopolístico da geração e da transferência de tecnologia para os países em desenvolvimento.

Vários são os autores que desenvolveram trabalhos pautados pelas premissas da teoria de "dependência". 6

O conceito refere-se a um tipo de relação dominação-subordinação entre estruturas capitalistas de países de desenvolvimento desigual, implicando em um mecanismo de geração, transmissão e absorção de excedentes, que favorece nitidamente aqueles países de desenvolvimento capitalista mais avançado. Essa relação de dependência foi elevada à categoria de uma "causa" do subdesenvolvimento, assumindo apenas formas diferentes nas diversas fases do desenvolvimento capitalista.
$\mathrm{Na}$ época do capitalismo concorrencial, a relação de dependência é estabelecida através do comércio internacional, apropriando-se as empresas estrangeiras do excedente, mediante a deterioração dos termos de troca. No capitalismo monopolista financeiro, novas formas financeiras para a apropriação do excedente são acrescentadas às anteriores, tais como os recursos de lucros e os pagamentos por conta da tecnologia (royalties), o que caracterizaria uma dependência predominantemente tecnológica e produtiva. Entretanto, a teoria da dependência, tal como a análise estruturalista, não oferece um quadro de referências conceitual que pudesse analisar e explicar o desenvolvimento capitalista a um nivel internacional,:inclusive as mudanças históricas' nas relações de dependência. A ênfase excessiva nas relações externas, como fator causal do subdesenvolvimento, leva a negligenciar a análise das estruturas internas, produtivas e políticas, que se desenvolvem e se reforçam mutuamente. Com referência à dependência tecnológica, a industrialização controlada pelo capital estrangeiro introduz técnicas capitalintensivo, monopolizando a produção e os mercados, e além de tornar quase impossível a emergência de uma burguesia industrial nacional, leva também, em conseqüência da concentração e centralização do capital, a formações políticas autoritárias e antipopulista.

Mesmo em situações onde o Estado e parte da burguesia nacional participam da industrialização, o poder decisório estaria ainda nas mãos das corporações transnacionais que controlam os centros financeiros e tecnológicos.

A produção e os mercados de tecnologia estão sob o controle de grupos oligopolísticos transnacionais, freqüentemente associados às minorias privilegiadas nos países subdesenvolvidos. Assim, a demanda por tecnologia é dirigida às fontes externas, o que implica em extrema fraqueza dos sistemas nacionais de pesquisa e desenvolvimento $(P+D)$, não ligados organicamente ao aparelho produtivo de seus respectivos países. Não dispondo de capacidade de produzir, adaptar ou escolher as tecnologias "apropriadas", os paises subdesenvolvidos carecem também de poder de barganha para escolher e comprar tecnologia nos mercados internacionais, onde prevalecem todos os tipos de barreiras (patentes, licenças, cláusulas contratuais, etc.) para o livre acesso ao know-how tecnológico, vendido a preços administrados, isto é, arbitrários, assegurando aos seus detendores rendas monopolísticas, enquanto representa nova drenagem de recursos para os países centrais.

\section{TECNOLOGIA E ACUMULAÇÃO DE CAPITAL EM ESCALA INTERNACIONAL}

Convém esboçar rapidamente as noções básicas de concentração econômica e seus produtos - os oligopólios - antes de passarmos à análise do processo de acumulação do Capital.

A concentração, definida pelos economistas de Cambridge, ${ }^{7}$ consiste num aumento do Capital, da produção e dos empregados de uma empresa, assumin- 
do ora a forma de concentração econômica, técnica ou financeira. A associação de recursos permite às empresas estabelecer um conjunto de diretrizes referentes a investimentos, produção e preços, que lhes confere poder e vantagens em seus respectivos mercados.

Oligopólios surgem quando o custo médio mínimo necessário para obter uma escala de produção eficiente e uma capacidade de utilização ótima são tais que só podem ser conseguidas mediante escalas de produção relativamente amplas, sendo o número de produtores capazes de formar oligopólios em cada ramo, necessariamente pequeno. A inovação tecnológica, nestes casos, contrariamente ao que acreditavam os clássicos (e continuam a afirmar os neo-clássicos) não se propaga a todas as firmas do ramo, servindo apenas ao oligopólio para obter lucros extraordinários.

A descontinuidade tecnológica, associada à apropriação da inovação pelos oligopólios, torna o acesso a novas técnicas praticamente impossivel para outras empresas, em virtude das escalas de produção e vendas que restrigem o número de alternativas tecnológicas. Assim, em vez de uma redução de preços, verifica-se um aumento dos lucros da empresa que controla a nova tecnologia. A tecnologia constitui, portanto, a base do poder oligopolístico, traduzido em certas escalas de produção e vendas. Uma das consequiências da concentração oligopolística, baseada no progresso técnico, é a tendência à redução do emprego, refletindo-se sobre a demanda e, em última linha, na produção. $\mathrm{Pa}$ ra evitar essa tendência que levaria à estagnação do sistema, as empresas procedem à diversificação e diferenciação de produtos, através do lançamento de novos produtos ou linhas de produtos, os quais virão reforçar a dominação tecnológica do oligopólio.

Enfim, é a dinâmica dos processos de concentração, diferenciação e diversificação da produção, em escala internacional, que leva os oligopólios (ou companhias multi ou transnacionais) a invadir os mercados dos paises subdesenvolvidos, tornando-os altamente concentrados e geradores de lucros elevados, apesar de suas dimensões e escalas reduzidas, por não depender de estruturas de custo ou da disponibilidade de recursos naturais. As operações das empresas oligopolisticas realizam-se com tecnologias e em escalas produtivas que são lucrativas, mesmo em mercados restritos, e a diferenciação e diversificação de produtos prossegue de acordo com os limites e características desses mercados.

Entretanto, qual é a causa da concentração e qual a função essencial da tecnologia na determinação dos custos de produção e na geração de lucros? Como entender a dinâmica das empresas capitalistas que constantemente são obrigadas a romper as fronteiras de seus mercados (aumentar a demanda), enquanto geram estruturas que as comprimem? A tentativa de uma resposta é esboçada no parágrafo seguinte.

\section{PROGRESSO TÉCNICO E ACUMULAÇĀO}

Se definimos tecnologia como conhecimento aplicado à produção, devemos também especificar a segunda como produção generalizada de mercadorias. Cada mercadoria tem seu "valor de uso" e também, um "valor de troca" contendo e representando uma relação social e um modo de produção historicamente específicos. Como fator de conhecimento aplicado à produção capitalista, a tecnologia adquire as características de uma mercadoria e seu desenvolvimento passa a ser determinado pelas relações sociais vigentes no sistema capitalista.

Por outro lado, o processo de produção capitalista é também produção de valor adicionado ou maisvalia, que permite aos proprietários dos meios de produção ampliar a quantia de dinheiro investido na produção e, através desta acumulação, manter seu status e poder como donos dos meios de produção.

Neste sentido, a produção capitalista é também reprodução do capital como relação social, obrigando o capitalista a acumular incessantemente valor adicionado. Tendo o dia de trabalho limites físicos e sociais, a forma de incrementar valor adicionado consiste em diminuir o tempo de trabalho necessário para a reprodução da força de trabalho, reduzindo o custo de vida dos trabalhadores.

Não podendo reduzir a remuneração monetária sempre quando lhe aprouver, o capitalista procura introduzir no processo produtivo mudanças sociais e técnicas que aumentam a produtividade do trabalho e, assim, levam à produção de mercadorias em menos tempo, com a conseqüente redução do valor da força de trabalho e do custo dos meios e materiais de produção.

O "progresso técnico", aumentando o valor adicionado do capitalista, favorece-o no conflito histórico com o operariado e, ao mesmo tempo, melhora sua posição competitiva face aos outros capitalistas concorrentes. $\mathrm{O}$ próprio processo de concentração econômica e a conseqüente divisão e especialização das tarefas, deixando nas mãos do capitalista e/ou de seus gerentes o conhecimento e o controle da atividade produtiva global, contribuem poderosamente, mediante as economias de escala, para a acumulação e, assim, a expansão do sistema produtivo. Ademais, a concentração e centralização do capital trazem em seu bojo a progressiva socialização do trabalho e dos meios de produção, estimulando poderosamente as forças produtivas da sociedade. Nisto reside a contradição fundamental do modo de produção capitalista, claramente visível na análise das funções da inovação tecnológica: a acumulação de capital acelera o progresso técnico mas, ao mesmo tempo, cria obstáculos ao seu pleno desenvolvimento por enquadrá-lo na lógica estreita dos lucros. Por outro lado, a tecnologia estimula e incentiva a acumulação, mas também a dificulta por elevar a composição técnica e orgânica do capital. Uma análise mais detalhada deste processo contraditório é apresentada no parágrafo seguinte sobre as características da inovação tecnológica.

\section{INOVAÇĀO DE PROCESSOS E DE PRODUTOS}

A produção, embora um processo contínuo, se dá por ciclos, bastante visíveis na agricultura, porém não menos reais nos outros setores da atividade econômica. 
É na passagem de um ciclo para outro que se tornam possíveis inovações tecnológicas, modificando a divisão social e as técnicas de trabalho, e elevando a produtividade do mesmo.

A inovação técnica abrange desde a descoberta de novas matérias-primas, a mudança nos métodos de produção, a criação de novos produtos e até a substituição dos equipamentos. Devido ao seu impacto diverso na economia, convém distinguir entre inovação de processo e inovação de produtos.

A primeira se origina geralmente no setor de bens de produção, com a fabricação de novos equipamentos ou de novas matérias-primas. Parte dessas inovaçōes servirá também ao setor de bens de consumo. $\mathrm{Na}$ medida em que um novo produto é difundido, ocorrem mudanças de processos, que reduzem os custos de produção do novo produto. Importa salientar que, tanto as inovaçð̃es de processos, quanto as de produtos, originam investimentos autônomos em cadeia, contribuindo assim para o crescimento da economia. As mudanças de processos tornam tecnicamente obsoletos certos meios de produção, antecipando sua reposição antes que eles estejam materialmente consumidos, enquanto novos produtos exigem investimentos em novas linhas de produção.

\subsection{As mudanças de processo}

A natureza das mudanças de processo é tal que reduz, geralmente, os custos de produção, mediante uma diminuição dos gastos com V (Capital variável ou salários) e um aumento C (Capital fixo).

Assim, os novos processos aumentam a produtividade fisica do trabalho, produzindo unidades a um custo menor, portanto, a um valor menor da mercadoria, à medida que diminui o tempo de trabalho necessário para produzi-la. Essa redução do trabalho vivo, sendo substituído por máquinas ("trabalho morto"), levaria, teoricamente, a uma queda da taxa de lucro.

As condições vigentes nas economias capitalistas contemporâneas - concorrência oligopolística e controle do volume e circulação da moeda pelo Estado permitem manter os preços constantes, com produtividade crescente. Por outro lado, aos oligopólios não interessa uma guerra de preços, levando-os a disputar o mercado mediante publicidade, diferenciação de produtos, etc., o que tende a manter os preços, apesar da inovação tecnológica e o conseqüente aumento de produtividade. Assim, ao contrário do que postulava a doutrina marxista, as mudanças de processo no capitalismo oligopolista não causam necessariamente uma queda na taxa de lucros.

Contudo, na medida em que os salários aumentam em relação ao capital fixo, seja devido a um crescimento da demanda por mão-de-obra ou de qualquer outro fator, as mudanças de processo tornam-se "econômicas", determinando assim, amplamente, o volume e as oscilações de emprego, na economia capitalista.
Pois, o aumento da produtividade induzido pelas mudanças de processo terá, normalmente, dois efeitos - ambos negativos - sobre o volume de emprego. Mantendo-se a demanda por bens de consumo no mesmo nivel - em consequeência da política de preços e salários da empresa - o volume de trabalho necessário para atender essa demanda tenderá a cair. Por outro lado, e como consequência do que precede, a mudança de processo acarreta uma redistribuição da renda a favor das camadas mais privilegiadas, e com isto, a propensão a consumir em toda economia tende a cair. Diminuindo o valor real da demanda por bens de consumo, criar-se-á uma situação de desemprego, tanto no setor de bens de consumo, quanto no de bens de produção, cuja demanda é derivada de demanda por bens de consumo. Em resumo, a mudança de processo, no período de implantação, aumenta o investimento e, em menor proporção, o consumo e o. emprego.

Porém, passado o período inicial de implantação, $o$ investimento e o consumo caem, em termos reais, assim como o emprego, tanto no setor de bens de consumo, quanto no de bens de produção. Contudo, o que evita a "reprodução contraida", ou as depressões cíclicas do sistema capitalista, são os novos produtos que resultam de inovações tecnológicas, e que tendem a elevar o consumo e, assim, o emprego.

Os efeitos conjuntos das inovações técnicas se equilibram mutuamente: enquanto os novos processos contraem o consumo, redistribuem a renda a favor do capital e, assim, reduzem o emprego, os novos produtos expandem o consumo, favorecem a elevação dos salários e fazem aumentar o emprego.

O surgimento de uma série de novos produtos eleva o emprego e acelera a acumulação, a qual induz uma reprodução ampliada, até o momento em que se manifestam limites materiais para a expansão, sob forma de escassez de certos produtos, matérias-primas ou mão-de-obra, o que eleva os custos da produção. $O$ aumento dos salários, devido a uma situação de pleno emprego, tornará as inovações de processos economicamente vantajosas, já que estas tendem a reduzir o nível real dos salários e de empregos.

\section{O SISTEMA DE PRODUÇÃO CAPITALISTA E O MERCADO INTERNACIONAL}

A configuração da economia internacional dominada pela lógica da acumulação capitalista é o produto dos processos de acumulação, concentração e centralização do capital, na busca de superar a contradição fundamental do sistema, manifesta na tendência ao declínio da taxa de lucro. Exportando parte do excedente constitui uma forma de acelerar a realização do valor $e$, assim, o crescimento do setor industrial. Com o avanço da industrialização e acumulação nós países centrais, tornou-se necessário aumentar a importação de matérias-primas e alimentos dos países periféricos, os quais - incorporando custos de produção mais baixos - permitiam a desvalorização da força de trabalho e a depressão do valor dos elementos do capital constante, com um conseqüente aumento dos lucros $e$ da acumulação. 
Assim. o desenvolvimento do capitalismo produziu, desde seu início, o problema do desenvolvimento desigual entre agricltura e indústria, campo e cidade, ou países especializando-se na produção de um ou outro setor.

Os mercados externos possibilitaram aos capitais deslocar-se para aqueles países onde as condiçðes de lucratividade foram melhores, sem preocupar-se excessivamente com o desenvolvimento harmonioso e equilibrado dos setores industrial e agrícola. A divisão internacional de trabalho estabelecida entre países exportadores de produtos primários por um lado, e aqueles exportadores de bens manufaturados por outro, tendeu a manter essas condiçðes desiguais, que permitiam a geração de um excedente nos países centrais, neles reduzindo a valor dos elementos variáveis $e$ constantes, responsáveis pela taxa de lucro, enquanto possibilitou também uma elevada taxa de lucro, nos países periféricos. Os países periféricos, com mercados apenas incipientes, pouco representam na fase inicial da expansão do sistema, para a absorçăo do excedente. Sua função precípua é dar suporte à industrialização nos paises centrais, constituindo-se em mercados apenas na fase de sua própria industrialização. Esta tem coincidido, geralmente, com a concentração e centralização do capital nos países centrais, exigindo a lógica da acumulação a canalização de investimentos e a eventual transferência de atividades industriais para os paises periféricos, de uma forma sistemática e planejada.

A internacionalização de certas atividades produtivas, se por um lado significa uma tentativa de superar a contradição fundamental do desenvolvimento desigual capitalista - a geração cada vez mais acelerada de um excedente, face as dificuldades de sua realização -, tende, todavia, a reproduzir os mesmos problemas e conflitos nos países periféricos em "vias de desenvolvimento".

IVide Rattner, H. Second working paper. Sussex, 1976, mimeo.

2 Vide Solow, R. M. Technical change and the aggregate production function. Review of Economics and Statistics. V. 39.

3 Vide, entre outros, Solow, R. M. Investment and technical progress. Matematical Methods in the Social Sciences. J. K. Arrow progress. Manford University Press, Stanford, Ca, 1969; Massel, B. F. Investment, innovation and growth. Econometria. V. 40, abril 1962.

4 Vigil, F. Gonzalez. La modelización neo classica del progresso tecnico y de la acumulacion de capital. Cuadernos. Universidad del. Pacífico, Série Ensayos n? 4, Lima, janeiro 1974.
5 Prebisch. R. El désarollo economico de América Latina y alguns de sus principales problemas. Bol. Econ. p. América Latina. V. VII, fev. 1961 ; Furtado, C. Desenvolvimento e estagnação na A. Latina. Rio, Civilização Brasileira, 1966; Pinto, A. Diagnósticos, estruturas y esquemas de desarollo en América Latina. Boletin de la Escuela Latino Americana de Sociologia. Chile, n. 5, 1970.

6 Vide, Cardoso, F. H. e Faletto, E. Dependencia e desenvolvimento na América Latina; Frank, A. G. Capitalism and under na America Lelopment in Latin American. Monthly Review Press. New York, 1967; Santos, Th. dos. El nuevo caracter de la dependencia - CESo. Chile, Cuaderno n. 1, 1968, Paz, P. Dependencia financeira y desnacionalizacion de la industria interna. ILPES, mimeo., junho 1969.

7 Vide, entre outros, Robson, J. The economics of imperfect competition. Mac Millan, London, 1933; Chamberlain, E. H. The theory of monopolistic competition. Harward University Press, Cambridge, Mass., 1948 (6th Edition).

\section{BIBLIOGRAFIA}

Furtado, C. Um projeto para o Brasil. Rio. Edit. Saga
Subdesenvolvimento e estagnação na América Latina. Rio, Civilização Brasileira, 1966.

Galbraith, J. K. The new industrial state. Boston, Houghton Mifflin, 1967.

Kindleberger, Ch. P. Comércio exterior e a economia nacional. Rio, Fundo de Cultura, 1967 (traduzido do inglês).

Riviére, M. Economia burguesa e pensamento tecnocrático. Rio, Civilização Brasileira, 1966.

Salamo, P. Un procés de sous-developpement. Paris, F. Maspero, 1976.

Schumpeter, J. A. Teoria do desenvolvimento econômico. Rio, Fundo de Cultura, 1961.

Singer, P. I. Elementos para uma teoria de emprego aplicável a países não desenvolvidos. São Paulo, 1970, Cadernos CEBRAP 18.

. Emprego, produção e reprodução da força de trabalho. São Paulo, CEBRAP, mimeografado, 1976.

Technology, development and industrialization. Sussex. Projeto STPI, junho 1976, mimeo. 